\title{
Changes of major chemical components in larch wood through combined treatment of drying and heat treatment using superheated steam
}

\author{
Yonggun Park ${ }^{1}$ - Soo-Kyeong Jang ${ }^{1} \cdot$ Jun-Ho Park ${ }^{2}$ Sang-Yun Yang ${ }^{1}$ • \\ Hyunwoo Chung ${ }^{1} \cdot$ Yeonjung Han $^{3} \cdot$ Yoon-Seong Chang $^{3} \cdot$ In-Gyu Choi $^{1,4,5}$. \\ Hwanmyeong Yeo $^{1,4}$
}

Received: 1 February 2017 / Accepted: 13 July 2017/Published online: 4 August 2017

(C) The Japan Wood Research Society 2017

\begin{abstract}
The effects of the combined treatment of drying and heat treatment using superheated steam (SHS) were studied relative to the changes of the major chemical components in larch wood. The green lumber was dried and heat-treated in SHS conditions of $250{ }^{\circ} \mathrm{C}$ and $0.5 \mathrm{MPa}$ for $18 \mathrm{~h}$, and the relative percentage contents of sugars, lignin, and extractives were investigated and compared with the relative percentage contents in the lumber heattreated in hot air conditions of $250{ }^{\circ} \mathrm{C}$ and atmospheric pressure for $18 \mathrm{~h}$. After both heat treatment methods, the relative percentage contents of xylan, mannan, galactan, and arabinan were greatly decreased, whereas that of the Klason lignin was increased, additionally that of glucan and extractives remained almost unchanged. Lignin may bind with furan compounds decomposed from hemicellulose following heat treatment, thus contributing to the
\end{abstract}

Hwanmyeong Yeo

hyeo@snu.ac.kr

1 Department of Forest Sciences, College of Agriculture and Life Sciences, Seoul National University, 1, Gwanak-ro, Gwanak-gu, Seoul 08826, Republic of Korea

2 Materials R\&D Center, Samsung SDI Co., LTD., 130, Samsung-ro, Yeongtong-gu, Suwon-si, Gyeonggi-do 16678, Republic of Korea

3 Department of Forest Products, National Institute of Forest Sciences, 57, Hoegi-ro, Dongdaemun-gu, Seoul 02455, Republic of Korea

4 Research Institute of Agriculture and Life Sciences, Seoul National University, 1, Gwanak-ro, Gwanak-gu, Seoul 08826, Republic of Korea

5 Institute of Green-Bio Science and Technology, Seoul National University, 1447, Pyeongchang-daero, Daehwamyeon, Pyeongchang-gun, Gangwon-do 25354, Republic of Korea increase in the apparent relative percentage contents of the Klason lignin. In addition, the condensate collected in the condenser after combined drying and heat treatment using SHS was investigated qualitatively and quantitatively by high-performance liquid chromatography (HPLC). A large amount of furfural and acetic acid decomposed from hemicellulose was detected and some sugar components composed of cellulose and hemicellulose were detected in the liquid condensate.

Keywords Combined treatment - Superheated steam . Wood component - Wood drying - Wood heat treatment

\section{Introduction}

Wood heat treatment is a method of heating to temperatures of $160-260{ }^{\circ} \mathrm{C}$ that induces changes in the chemical composition of wood by thermal hydrolysis to improve the physico-mechanical properties and decay resistance of wood [1]. The heat-treated wood has some advantages, such as the improvement of dimensional stability with an increase of hydrophobicity, equalization of surface color, and increase of decay resistance. Because of these advantages, various heat treatment methods have been developed mainly in Europe, and the properties of wood heat-treated by each method have been investigated [2-4].

Wood heat treatment changes the chemical components of wood by degrading cell wall components or extractives. The chemical component changes from heat treatment depend on the time and temperature of the heat treatment, the species, and the type of heat treatment (heat transfer medium) [5-8]. In general, below $150{ }^{\circ} \mathrm{C}$, the wood dries beginning with the loss of free water and finishing with bound water. At $160-260{ }^{\circ} \mathrm{C}$, the main temperature range of 
heat treatment, wood undergoes various chemical component changes. The chemical changes of wood at these temperatures are mainly due to auto-catalytic reactions of the cell wall constituents [9]. First, hemicellulose, which is the most sensitive to heat among the wood cell wall components, degrades by deacetylation, followed by depolymerization catalyzed by released acetic acid [10, 11]. Cellulose is less affected by the heat treatment, probably because of its crystalline nature [11]. Heat treatment also causes the cleavage of the $\beta-O-4$ linkage of lignin [12]. Extractives such as resin acids were disappeared from the wood at temperatures above $200{ }^{\circ} \mathrm{C}$ [13]. In addition, at above $260{ }^{\circ} \mathrm{C}$, wood starts the carbonization with generating pyrolysis products, such as carbon dioxide [11].

Recently, the combined treatment of drying and heat treatment using superheated steam (SHS) for green wood has been studied. SHS, which is steam at a temperature above boiling point, has been used to dry wood, food, and sludge, etc [14]. The combined treatment of drying and heat treatment using SHS, which is called to "combined treatment", for green wood is the method that drying and heat treatment are carried out simultaneously using SHS at a high temperature and high pressure. Park et al. [15] carried out the combined treatment for green pitch pine using SHS at various temperatures and pressures on a lab scale, and determined the proper conditions for the temperature and pressure of SHS without the occurrence of drying checks. Because the combined treatment simultaneously carries out the two processes of drying and heat treatment in one reactor removed oxygen, it can decrease the time and energy required for the drying process and prevent fires.

This study investigated the changes of major chemical components in larch wood treated by combined treatment and compared them with those of wood treated by the conventional hot air heat treatment. In addition, the condensate collected in a condenser after the combined treatment was investigated qualitatively and quantitatively.

\section{Materials and methods}

\section{Materials}

Green larch (Larix kaempferi) lumber which was produced in Kangwon-do, Republic of Korea with a length of $2.2 \mathrm{~m}$ (longitudinal), a width of $150 \mathrm{~mm}$ (radial), and a thickness of $150 \mathrm{~mm}$ was prepared. Segments of $80 \mathrm{~mm}$ in length were removed from each end of the lumber to make the initial moisture content along the longitudinal direction uniform; pieces of $20 \mathrm{~mm}$ in length were cut from each end of the remaining lumber to evaluate the initial moisture content of the lumber; and the remaining lumber with the length of $2 \mathrm{~m}$ was subjected to heat treatment. A sample with a thickness of $20 \mathrm{~mm}$ was used to evaluate the major components of the non-treated wood after evaluating the initial moisture content. The average initial moisture content of 20 pieces of lumber was $40.0 \%( \pm 3.7)$. Ten pieces of lumber were used in each heat treatment method.

\section{Heat treatment equipment}

Hot air heat treatment for kiln-dried lumber and combined treatment for green lumber were carried out with the heat treatment equipment (Hanwoul Engineering Co., Gunpo-si, Republic of Korea) as shown in Fig. 1. The equipment was composed of a reactor, a condenser, a vacuum pump, and a water feed-tank. The cylindrical reactor with a diameter of $640 \mathrm{~mm}$, a length of $640 \mathrm{~mm}$, and a volume capacity of $0.7 \mathrm{~m}^{3}$ has a ceramic heater at the inner surface to heat the air or steam in the reactor. The outer surface of the reactor is insulated with grass wool to minimize the loss of heat in the reactor. Three fixed temperature sensors (K-type thermocouple, Fluke, WA, USA) to measure the temperature of the air or steam in the reactor, three flexible temperature sensors to measure the temperature in the wood or on the wood surface, and one pressure sensor (PA21SR, Keller, $\mathrm{NC}$, USA) to measure the pressure of the air or steam in the reactor are installed in the reactor. The measured values of the temperature and pressure are monitored in real time and recorded on the connected computer. In addition, three regulators are installed on the top of the reactor. Because all pipes connect the reactor to the condenser, all chemicals decomposed and water removed from the lumber are collected in the condenser. The vacuum pump is used to remove the air in the reactor before the beginning of the combined treatment, and the water feed-tank is used to inject distilled water into the reactor for generating SHS in the combined treatment.

\section{Combined drying and heat treatment by SHS}

In the combined treatment, SHS is generated in the reactor by boiling the injected distilled water [15]. The procedures for the combined treatment are as follows: after the reactor, with 10 pieces of stacked lumber, is made airtight, some distilled water is injected into the reactor. The amount of distilled water depends on a specific volume of SHS at the target temperature and target pressure and the volume capacity of the reactor. In this study, the target temperature of the SHS was set to $250{ }^{\circ} \mathrm{C}$, the temperature of the lumber reached $220{ }^{\circ} \mathrm{C}$ at this $\mathrm{SHS}$ temperature, and the target pressure of the SHS was set to $0.5 \mathrm{MPa}$ (absolute pressure). In this condition, the specific volume of SHS is $474 \mathrm{~L} / \mathrm{kg}$ and the volume capacity of the reactor is $700 \mathrm{~L}$. Therefore, the amount of distilled water to be injected into the reactor is 


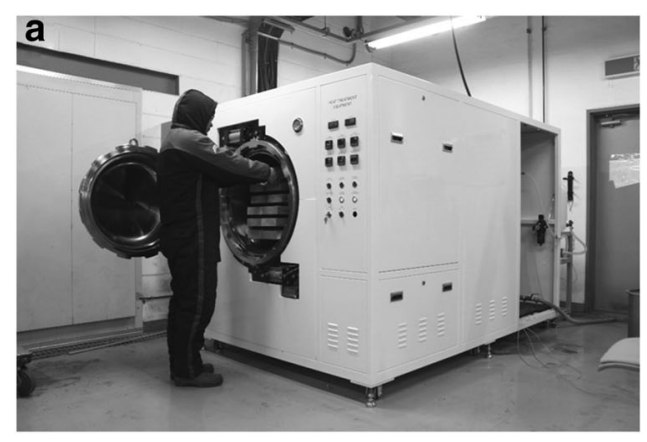

b
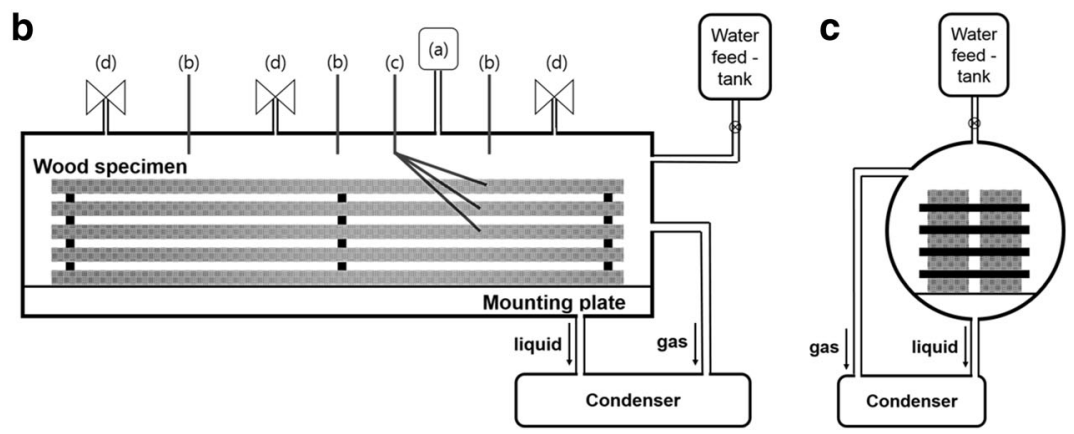

Fig. 1 Wood heat treatment equipment [19]. A Overall view of the equipment. B Side view of the reactor. $a$ Pressure sensor for measuring steam pressure. $b$ Temperature sensors for measuring

calculated as $1.5 \mathrm{~kg}$. Nevertheless, to fill up the reactor with steam quickly at the beginning of the process, a larger amount was necessary. After injecting $3 \mathrm{~kg}$ of distilled water, the air in the reactor was removed. When the absolute pressure was dropped to below $0.01 \mathrm{MPa}$, the heater was operated to boil the water in the reactor. By evaporating the water in the reactor, the pressure in the reactor and the temperature of the steam were increased, and the reactor was then filled with SHS. The temperature of the SHS was maintained by the On/Off system of the heater, which was shut off when the temperature of the SHS reached the target temperature, and was the system re-operated when the temperature of the SHS dropped to below the target temperature. In addition, the pressure of the SHS was maintained while drawing off excess steam through regulators when the steam pressure reached the target pressure. The operation time of the heater was $18 \mathrm{~h}$. The total oven dry weight of the lumber used in the combined treatment was estimated to be $81.0 \mathrm{~kg}$.

\section{Heat treatment by hot air after the conventional kiln drying}

Because when green lumber was heat-treated by hot air at atmospheric pressure, some severe drying checks occurred in the wood, the lumber dried to approximately $12 \%$ of the moisture content was used in the conventional hot air heat treatment [15]. Therefore, 10 green larch lumber pieces were kiln-dried to $12 \%$ of the moisture content according to the FPL conventional kiln drying schedule and heat-treated by hot air of $250{ }^{\circ} \mathrm{C}$ with the equipment used in the combined treatment (Fig. 1). Unlike the combined treatment, the reactor was not made airtight. It was possible to exhaust the air in the reactor and the vapor removed from the lumber. The operation time of heater was $18 \mathrm{~h}$. The total oven dry weight of the lumber used in the conventional hot air heat treatment was estimated to be $86.8 \mathrm{~kg}$. steam temperature. $c$ Temperature sensors for measuring wood temperature. $d$ Pressure regulators. C Front view of the reactor

\section{Analysis of major chemical components in larch lumber}

The chemical composition of the lumber before both heat treatments was supposed to be same as that of the pieces of $20 \mathrm{~mm}$ in length to evaluate the initial moisture content of the lumber. The chemical composition of the lumber after both heat treatments was also supposed to be the same as that of the pieces of $20 \mathrm{~mm}$ in length cut from the center of the lumber along the longitudinal direction after the heat treatment. All pieces were milled to below $0.5 \mathrm{~mm}$ and used to estimate the changes of major chemical components before and after both heat treatment methods. When the milled samples were extracted with alcohol-benzene $(1: 2, \mathrm{v} / \mathrm{v})$ solution, the amount of chemicals extracted from the solution was considered to be the amount of extractives of the larch lumber. The analytical procedure for estimating amount of Klason lignin, acid soluble lignin (ASL), and sugars was performed with reference to the previous studies [16-18]. The samples of alcohol-benzene-extracted solid residue $(0.3 \mathrm{~g})$ were swelled in $3 \mathrm{~mL}$ of $72 \%$ sulfuric acid at $30{ }^{\circ} \mathrm{C}$ for $1 \mathrm{~h}$ and later added to $84 \mathrm{~mL}$ distilled water for dilution (4\% sulfuric acid). These samples were reacted in an autoclave at $121^{\circ} \mathrm{C}$ for $1 \mathrm{~h}$ and were filtered using distilled water through glass filters $(1 \mathrm{G} 4$, Iwaki, Japan). The residue on the filters was oven-dried and weighed for measuring Klason lignin [16]. To analyze chemical components of the residue after Klason lignin method, pyrolysis gas chromatography/spectrograph (pyrolysis-GC/MS) analysis was carried out. For pyrolysis-GC/MS analysis, $2 \mathrm{mg}$ of sample was put into a quartz tube with a $2.6 \mu \mathrm{g}$ of an internal standard (fluoranthene). Then, it was pyrolyzed using CDS Pyroprobe 5000 (CDS Analytical Inc., Oxford, PA, USA) at $600{ }^{\circ} \mathrm{C}$ for $20 \mathrm{~s}$ with a heating rate of $10^{\circ} \mathrm{C} / \mathrm{ms}$ in helium gas, which is a representative inert atmosphere. Released volatile products were analyzed by gas 
chromatography (Agilent Technologies 7890A) with a mass selective detector (Agilent Technologies 5975A). ASL was analyzed by the absorbance of the filtrate which was determined using a UV-visible spectrophotometer (UV-1601 PC, Shimadzu, Japan). The filtrates were diluted with distilled water $(1: 14, \mathrm{v} / \mathrm{v})$, and the absorbance was measured at $205 \mathrm{~nm}$ with a quartz cuvette [17]. The amount of sugars (glucan, xylan, mannan, galactan, and arabinan) in the filtrate after Klason lignin method was determined by a bio-liquid chromatograph (ICS-2500, Thermo Dionex, Palo Alto, CA, USA) outfitted with a CarboPac PA-1 column $(250 \times 4 \mathrm{~mm}$, Dionex, Palo Alto, CA, USA) and a pulsed amperometry detector (HP 1100, Hewlett Packard, USA) [18]. The evaluation of the major chemical components in lumber was carried out along the procedures in Fig. 2.

\section{Analysis of condensate collected in condenser after combined treatment using SHS}

In the combined treatment, unlike the conventional hot air heat treatment, the chemicals decomposed from lumber by heat treatment can be recovered in the condenser. The condensate recovered in the condenser was classified as the gas condensate with excess steam drawn off through regulators during the combined treatment and the liquid condensate condensed in the reactor and recovered in the condenser through a discharge pipe after combined treatment. Because various effective components were included in the chemicals decomposed by heat treatment according to the previous studies, two types of condensates were analyzed qualitatively and quantitatively by high-performance liquid chromatography (HPLC). Dionex Ultimate 3000 (USA) was used in the HPLC analysis. RI (ERC, RefractoMAX520, Japan) was used as a detector, and an Aminex $87 \mathrm{H}$ column was used. The chemicals were analyzed in the HPLC oven, which was set to $40{ }^{\circ} \mathrm{C}$ with the rate of $0.5 \mathrm{ml} / \mathrm{min}$ for $90 \mathrm{~min}$.

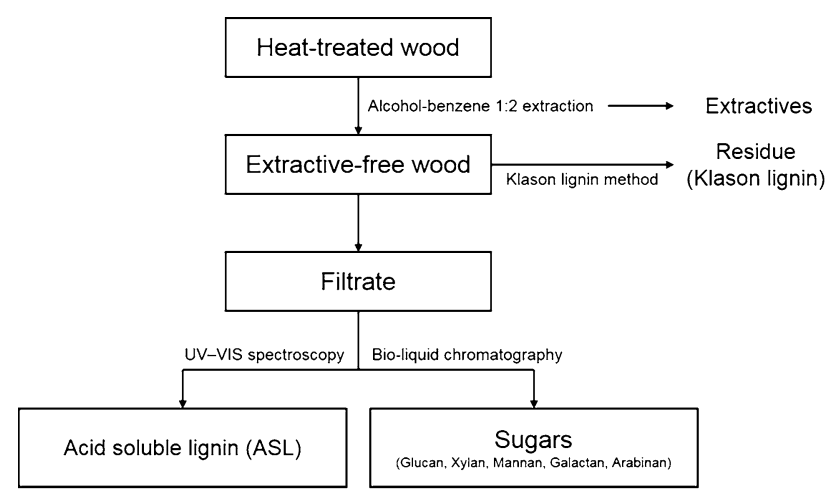

Fig. 2 Procedures for analyzing major components in larch lumber

\section{Results and discussion}

\section{Combined drying and heat treatment by SHS (combined treatment)}

Figure 3 shows changes of the temperature and pressure of SHS in the reactor and temperature of the lumber during the combined treatment for green larch lumber. At the beginning of the combined treatment, the temperature and pressure of the SHS and temperature of the lumber increased rapidly. When the temperature and pressure of the SHS reached the target temperature $\left(250^{\circ} \mathrm{C}\right)$ and the target pressure $(0.5 \mathrm{MPa})$, the temperature of the lumber reached the saturation temperature $\left(151.8^{\circ} \mathrm{C}\right)$ of steam at $0.5 \mathrm{MPa}$ and was maintained for $3 \mathrm{~h}$. Park et al. [19] reported that the wood specimen was oven-dried when the temperature of the wood specimen was maintained constantly and re-increased. In other words, the water in the wood was completely removed for the duration of the constant temperature, and the temperature of the wood was re-increased by the heat energy which had been used to remove the water in the wood was used to heat the wood. The temperature of the lumber reached $220{ }^{\circ} \mathrm{C}$ at the end of the combined treatment. Considering that the temperature range inducing changes of the chemical components of wood by heat treatment is $160-260{ }^{\circ} \mathrm{C}$, the lumber was heat-treated for $10 \mathrm{~h}$. The final moisture content of the lumber after the combined treatment was almost $0 \%$. The total oven dry weight of the treated lumber was $73.9 \mathrm{~kg}$, and $7.1 \mathrm{~kg}$ of the mass was lost.

\section{Heat treatment by hot air}

Figure 4 shows the changes of the temperature and pressure of hot air in the reactor and temperature of the lumber during the hot air heat treatment for kiln-dried larch lumber. At the beginning of the hot air heat treatment, the temperature of the air and lumber was increased rapidly; however, the pressure of the air maintained and

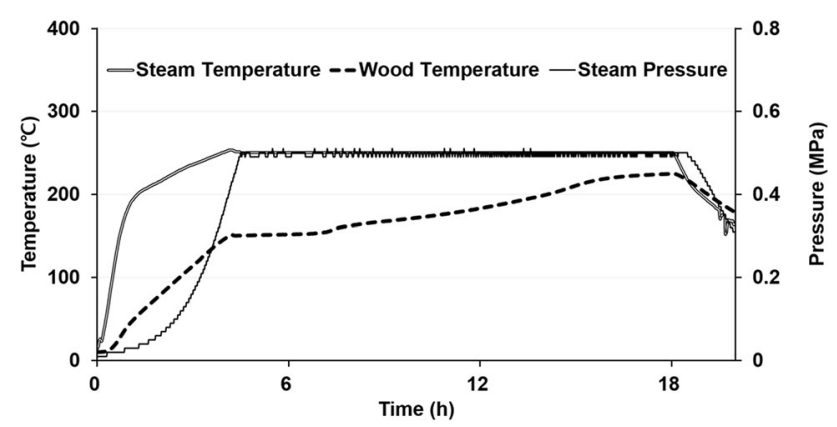

Fig. 3 Changes of temperature and pressure of SHS in the reactor and temperature in the lumber during combined treatment (target conditions of steam: $0.5 \mathrm{MPa}$ and $250{ }^{\circ} \mathrm{C}$ ) 


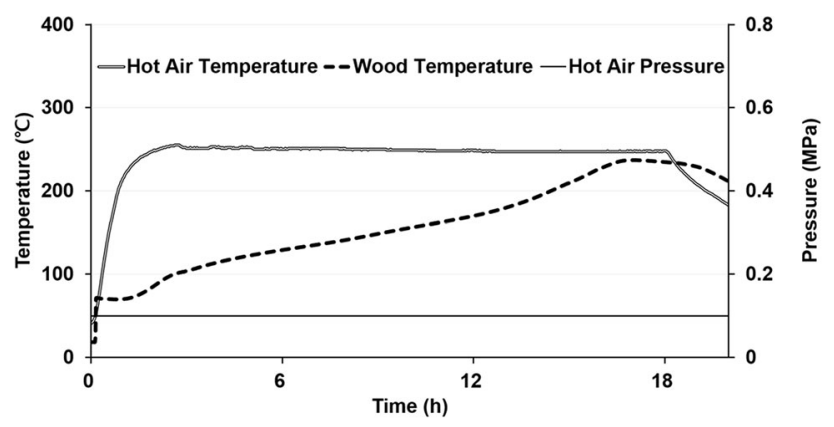

Fig. 4 Changes of temperature and pressure of steam in the reactor and temperature in the wood specimen during the hot air heat treatment (target conditions of the hot air: atmospheric pressure and $\left.250{ }^{\circ} \mathrm{C}\right)$

atmospheric pressure. The temperature of the lumber almost increased to the maximum temperature $\left(220^{\circ} \mathrm{C}\right)$ without the duration of constant temperature in the hot air heat treatment, unlike the combined treatment. This is why the heat energy to remove water in the lumber in the hot air heat treatment for kiln-dried lumber was much smaller than that of the combined treatment for green lumber. The duration that the lumber was heat-treated, in which the temperature of the lumber was maintained above $160{ }^{\circ} \mathrm{C}$, was $10 \mathrm{~h}$. After the hot air heat treatment, the final moisture content of the lumber was $0 \%$. The total oven dry weight of the treated lumber was $71.5 \mathrm{~kg}$, and $15.3 \mathrm{~kg}$ of the mass was lost.

\section{Analysis of major chemical components in larch lumber}

Table 1 shows the relative percentage contents of the major chemical components in larch lumber before and after the combined treatment and hot air heat treatment. Although different heat transfer mediums were used in the two different heat treatment methods, the changes of the relative percentage contents of the major chemical components in larch lumber before and after heat treatment were very similar. In both cases, after heat treatment, the relative percentage contents of the glucan and extractives were almost unchanged or slightly decreased. However, there was a large decrease in the relative percentage contents of the xylan, mannan, galactan, and arabinan, which are known for component of the hemicellulose and a large increase in the relative percentage contents of the Klason lignin compared with before heat treatment.

Hemicellulose is known as the most sensitive among the wood cell wall components. According to the previous studies, the degradation starts with deacetylation, and the released acetic acid acts as a depolymerization catalyst that further increases polysaccharide decomposition [10, 11]. Acid-catalyzed degradation leads to the formation of formaldehyde, furfural, and other aldehydes [20]. At the same time, hemicellulose undergoes dehydration reactions with the decrease of hydroxyl groups [21].

The relative percentage contents of Klason lignin were increased. However, the lignin determined by the Klason lignin method, which is a standard method to measure the amount of lignin, is probably not native lignin. According to the previous studies, polycondensation reactions with other cell wall components, resulting in further crosslinking, contribute to the increase in the apparent relative percentage contents of lignin [3, 9, 10, 22]. Based on the oven dry weight $(81.0 \mathrm{~kg})$ of the lumbers before the combined treatment and the relative percentage content of the Klason lignin $(28.8 \%)$, the calculated weight of the Klason lignin of the lumbers before the combined treatment was $23.3 \mathrm{~kg}$. On the other hand, the calculated weight of the Klason lignin of the lumbers after the combined treatment was $41.1 \mathrm{~kg}$. Considering that the absolute amount of lignin would not increase following heat treatment, the increase in the amount of the Klason lignin may result from the increase in the amount of the residue, which was not dissolved by $\mathrm{H}_{2} \mathrm{SO}_{4}$ after the Klason lignin method due to cross-linking with lignin and some other chemicals

Table 1 Relative percentage contents of the major chemical components in larch lumber before and after combined treatment and hot air heat treatment

\begin{tabular}{llllll}
\hline Major chemical components in larch lumber & \multicolumn{2}{l}{ Combined treatment } & & \multicolumn{2}{l}{ Hot air heat treatment } \\
\cline { 2 - 3 } & Before treatment $(\%)$ & After treatment $(\%)$ & Before treatment $(\%)$ & After treatment $(\%)$ \\
\hline Glucan & 37.5 & 34.9 & 0.0 & 33.8 & 34.3 \\
Arabinan & 2.1 & 0.3 & 2.7 & 0.2 \\
Galactan & 10.9 & 1.2 & 17.0 & 2.3 \\
Xylan & 3.6 & 3.9 & 3.5 & 1.2 \\
Mannan & 11.8 & 55.6 & 9.9 & 4.3 \\
Klason lignin & 28.8 & 0.3 & 28.4 & 54.1 \\
Acid soluble lignin & 0.4 & 3.8 & 0.3 & 0.4 \\
Extractives & 4.9 & 4.4 & 3.2 \\
\hline
\end{tabular}


(possibly chemicals decomposed from hemicellulose). Figure 5 shows the chromatographs of pyrolysis/GC/MS for the Klason lignin before and after the combined treatment. Unlike the Klason lignin of non-treated larch lumber, some furan compounds such as 2-methylfuran, 2,5dimethylfuran, 2-ethyl-5-methylfuran, and 5-methyl-2-furancarboxaldehyde were detected within $15 \mathrm{~min}$ of reaction time. These furan compounds seemed to be decomposed from hemicellulose following heat treatment and bound to lignin. The furan-lignin compounds were not dissolved by $\mathrm{H}_{2} \mathrm{SO}_{4}$ during the Klason lignin method and remained as a Klason lignin residue. Therefore, the presence of these furan-lignin compounds may be a reason why the amount of the Klason lignin appeared to be increased by heat treatment.

Cellulose was less affected by the heat treatment, probably because of its crystalline nature [11]. For this reason, there is almost no change in the relative percentage contents of glucan before and after the heat treatment.

There is also little change in the relative percentage of the extractives. However, because native extractives in the non-treated wood are very sensitive to heat, they were volatilized, degraded, and disappeared, and new compounds that can be extracted from wood appeared, resulting from the degradation of cell wall structural components $[3,13,23]$.

\section{Analysis of condensates collected in condenser after combined treatment using SHS}

Figure 6 a shows the picture of the gas condensate, and Fig. 7a shows the picture of the liquid condensate collected in the condenser after the combined treatment using SHS. A total of $20.5 \mathrm{~kg}$ of yellow gas condensate and $4.9 \mathrm{~kg}$ of brown liquid condensate were collected in the condenser.

Figure $6 \mathrm{~b}$ shows the results of the HPLC analysis for gas condensate. There are five peaks, which represent formic acid, acetic acid, levulinic acid, 5-hydroxymethylfurfural, and furfural in order from the left, respectively (Table 2). The amount of furfural was the highest in the liquid condensate, and a large amount of acetic acid degraded from hemicellulose was also included.
Fig. 5 Pyrolysis GC/MS chromatographs for Klason lignin. a Klason lignin of larch lumber before combined treatment. b Klason lignin of larch lumber after combined treatment
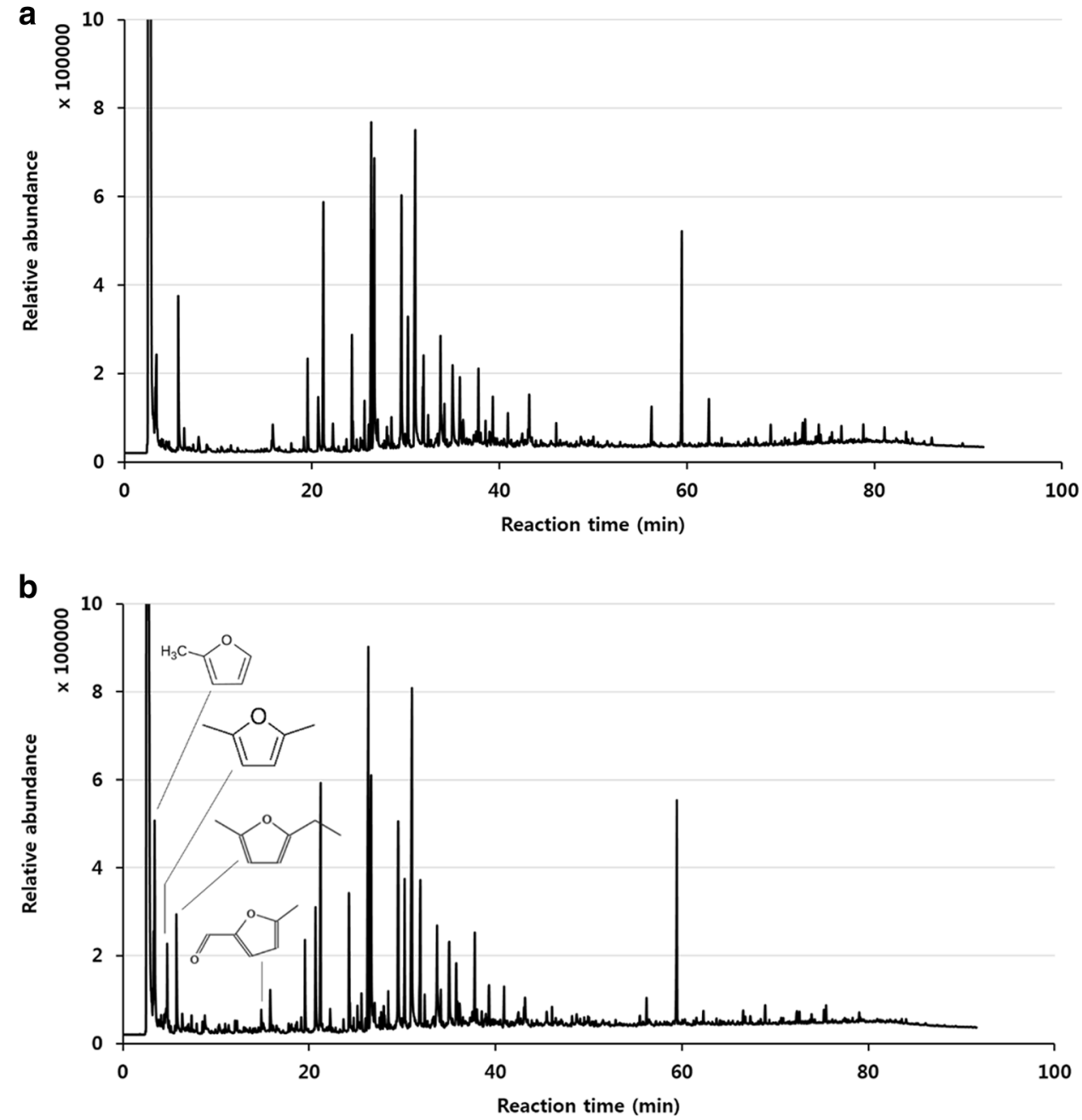
Fig. 6 Gas condensate collected in the condenser during the combined treatment. a Gas condensate. b HPLC analysis for gas condensate
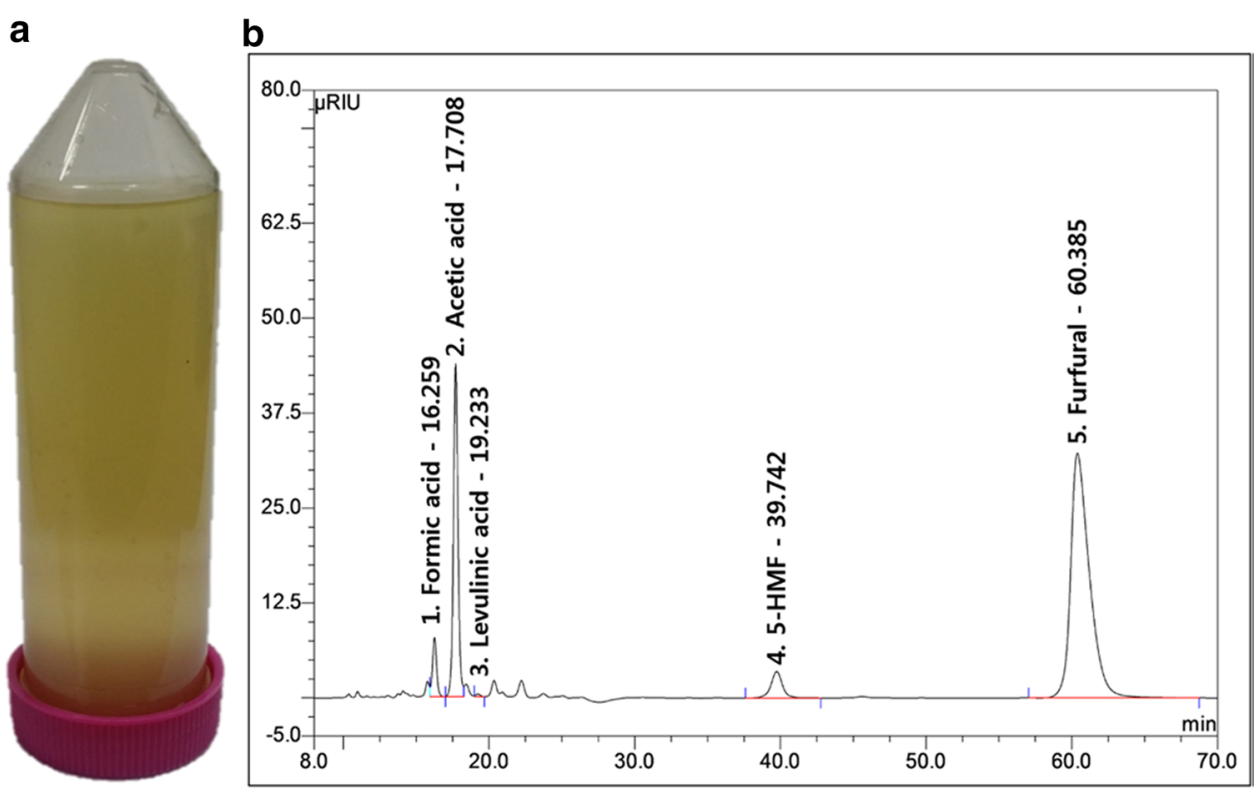

Fig. 7 Liquid condensate collected in the condenser after the combined treatment. a Liquid condensate. b HPLC analysis for liquid condensate a

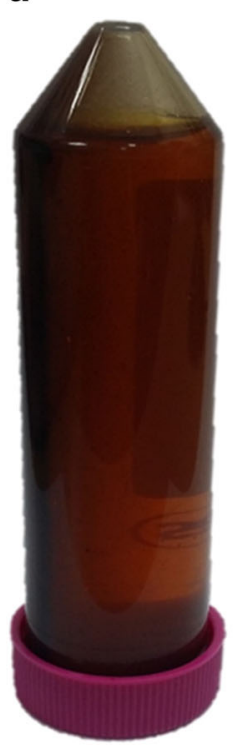

b

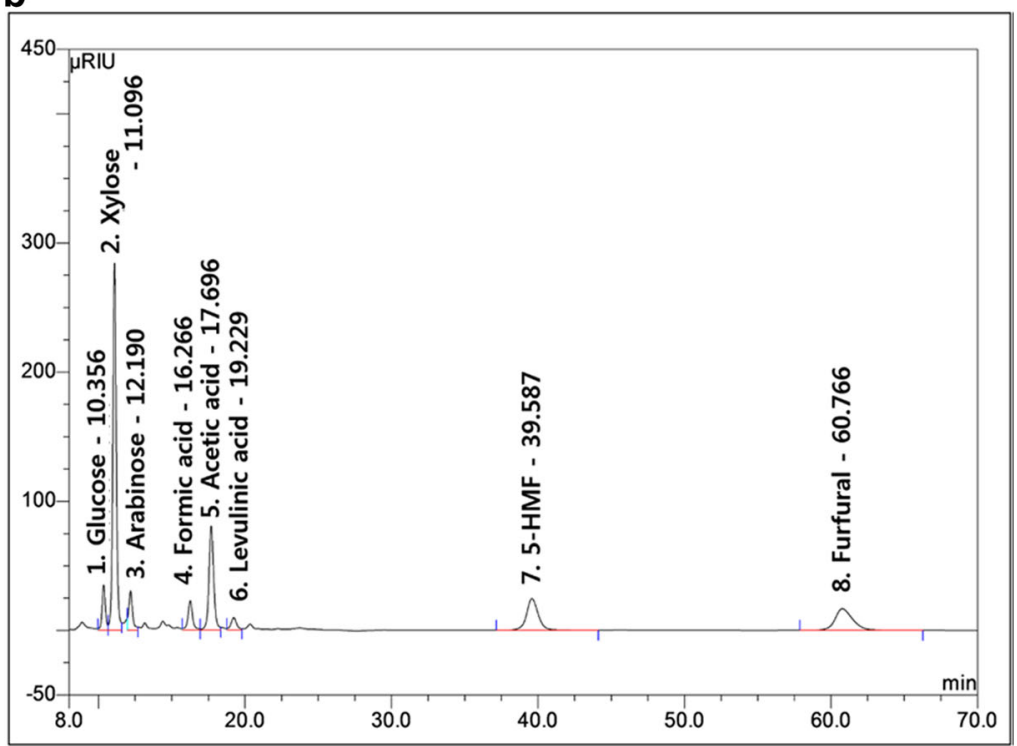

Table 2 Chemical name and content in gas condensate by HPLC analysis

\begin{tabular}{lllr}
\hline No. & Retention time $(\mathrm{min})$ & Chemical name & Chemical content $(\mathrm{mg} / \mathrm{L})$ \\
\hline 1 & 16.26 & Formic acid & 2508.2 \\
2 & 17.71 & Acetic acid & $11,818.5$ \\
3 & 19.23 & Levulinic acid & 59.5 \\
4 & 39.74 & 5-Hydroxymethylfurfural & 881.0 \\
5 & 60.39 & Furfural & $15,750.6$ \\
\hline
\end{tabular}

Chemical content means weight $(\mathrm{mg})$ of chemical per $1 \mathrm{~L}$ of condensate $H P L C$ high-performance liquid chromatography
Figure $7 \mathrm{~b}$ shows the results of the HPLC analysis for liquid condensate; there are eight peaks, which represent glucan, XMG (xylan + mannan + galactan), arabinan, formic acid, acetic acid, levulinic acid, 5-hydroxymethylfurfural, and furfural in order from the left, respectively (Table 3). The amount of XMG, which did not exist in the 
Table 3 Chemical name and content in liquid condensate by HPLC analysis

\begin{tabular}{lllr}
\hline No. & Retention time $(\mathrm{min})$ & Chemical name & Chemical content $(\mathrm{mg} / \mathrm{L})$ \\
\hline 1 & 10.36 & Glucan & 3166.9 \\
2 & 11.10 & XMG & $27,764.9$ \\
3 & 12.19 & Arabinan & 3235.2 \\
4 & 16.27 & Formic acid & 8092.4 \\
5 & 17.70 & Acetic acid & $22,595.7$ \\
6 & 19.23 & Levulinic acid & 2047.2 \\
7 & 39.59 & 5-Hydroxymethylfurfural & 6254.9 \\
8 & 60.77 & Furfural & 7690.5 \\
\hline
\end{tabular}

Chemical content means weight $(\mathrm{mg})$ of chemical per $1 \mathrm{~L}$ of condensate

$H P L C$ high-performance liquid chromatography, $X M G$ xylan + mannan + galactan

Table 4 Mass balance of chemical composition before and after combined treatment by superheated steam and hot air heat treatment

\begin{tabular}{|c|c|c|c|c|c|c|c|c|}
\hline \multirow{3}{*}{$\begin{array}{l}\text { Major component of wood } \\
\text { Glucan }\end{array}$} & \multicolumn{4}{|c|}{ Combined treatment by SHS } & \multicolumn{4}{|c|}{ Hot air heat treatment } \\
\hline & \multicolumn{2}{|c|}{ Before treatment } & \multicolumn{2}{|c|}{ After treatment } & \multicolumn{2}{|c|}{ Before treatment } & \multicolumn{2}{|c|}{ After treatment } \\
\hline & $30.4 \mathrm{~kg}$ & $(37.5 \%)$ & $25.8 \mathrm{~kg}$ & $(31.8 \%)$ & $29.3 \mathrm{~kg}$ & $(33.8 \%)$ & $24.5 \mathrm{~kg}$ & $(28.3 \%)$ \\
\hline Arabinan & $1.7 \mathrm{~kg}$ & $(2.1 \%)$ & $0.0 \mathrm{~kg}$ & $(0.0 \%)$ & $2.3 \mathrm{~kg}$ & $(2.7 \%)$ & $0.2 \mathrm{~kg}$ & $(0.2 \%)$ \\
\hline Galactan & $8.8 \mathrm{~kg}$ & $(10.9 \%)$ & $0.2 \mathrm{~kg}$ & $(0.3 \%)$ & $14.8 \mathrm{~kg}$ & $(17.0 \%)$ & $1.6 \mathrm{~kg}$ & $(1.9 \%)$ \\
\hline Xylan & $2.9 \mathrm{~kg}$ & $(3.6 \%)$ & $0.9 \mathrm{~kg}$ & $(1.1 \%)$ & $3.1 \mathrm{~kg}$ & $(3.5 \%)$ & $0.9 \mathrm{~kg}$ & $(1.0 \%)$ \\
\hline Mannan & $9.6 \mathrm{~kg}$ & $(11.8 \%)$ & $2.9 \mathrm{~kg}$ & $(3.6 \%)$ & $8.6 \mathrm{~kg}$ & $(9.9 \%)$ & $3.1 \mathrm{~kg}$ & $(3.5 \%)$ \\
\hline Klason lignin & $23.3 \mathrm{~kg}$ & $(28.8 \%)$ & $41.1 \mathrm{~kg}$ & $(50.8 \%)$ & $24.6 \mathrm{~kg}$ & $(28.4 \%)$ & $38.7 \mathrm{~kg}$ & $(44.6 \%)$ \\
\hline Acid soluble lignin & $0.3 \mathrm{~kg}$ & $(0.4 \%)$ & $0.2 \mathrm{~kg}$ & $(0.2 \%)$ & $0.3 \mathrm{~kg}$ & $(0.3 \%)$ & $0.3 \mathrm{~kg}$ & $(0.3 \%)$ \\
\hline Extractives & $4.0 \mathrm{~kg}$ & $(4.9 \%)$ & $2.8 \mathrm{~kg}$ & $(3.4 \%)$ & $3.8 \mathrm{~kg}$ & $(4.4 \%)$ & $2.3 \mathrm{~kg}$ & $(2.6 \%)$ \\
\hline Gas condensate & - & - & $0.6 \mathrm{~kg}$ & $(0.8 \%)$ & - & - & - & - \\
\hline Liquid condensate & - & - & $0.4 \mathrm{~kg}$ & $(0.5 \%)$ & - & - & - & - \\
\hline Mass loss & - & - & $6.1 \mathrm{~kg}$ & $(7.5 \%)$ & - & - & $15.2 \mathrm{~kg}$ & $(17.6 \%)$ \\
\hline Total & $81.0 \mathrm{~kg}$ & $(100.0 \%)$ & $81.0 \mathrm{~kg}$ & $(100.0 \%)$ & $86.8 \mathrm{~kg}$ & $(100.0 \%)$ & $86.8 \mathrm{~kg}$ & $(100.0 \%)$ \\
\hline
\end{tabular}

SHS superheated steam

gas condensate, was the highest in the liquid condensate. It seems that these sugars degraded by heat treatment ran out in the liquid state from the lumber and were collected in the condenser. This is the evidence that hemicellulose is the most degraded component by heat treatment among the wood cell wall components.

\section{Mass balance of heat-treated wood}

Because some wood cell wall components are degraded by heat treatment, the oven dry weight of wood after heat treatment is smaller than the expected oven dry weight of wood before heat treatment. In the case of the conventional hot air heat treatment, volatile chemicals cannot recover, because they are volatilized and disappear into the surrounding air. Some liquid chemicals were used to recover; however, most of the chemicals burned out at the bottom of the reactor. On the other hand, in the case of the combined treatment, most of the volatile and liquid chemicals are dissolved in the SHS and can be recovered in the condenser. Therefore, when these chemicals are separated, refined, and re-used, the amount of mass loss by heat treatment can decrease. To quantitatively evaluate the amount of chemicals recovered in the combined treatment compared with that in the hot air heat treatment, the mass balances of chemicals on the basis of expected oven dry weight before heat treatment have to be compared with each other in the case of two heat treatment methods.

Table 4 shows the mass balance of each component on the basis of the expected oven dry weight of lumber before heat treatment, including oven dry weight and mass loss after the heat treatment. In the combined treatment, there were $7.1 \mathrm{~kg}$ of mass loss on the oven dry weight before and after heat treatment. If $0.8 \mathrm{~kg}$ of chemicals in the $20.5 \mathrm{~kg}$ of gas condensates and $0.4 \mathrm{~kg}$ of chemicals in the $4.9 \mathrm{~kg}$ of liquid condensates were separated, refined, and re-used, $1.2 \mathrm{~kg}$ of chemicals degraded from wood could be re-used and the mass loss could be decreased to $5.9 \mathrm{~kg}$. In the case 
of the hot air heat treatment, $15.3 \mathrm{~kg}$ of mass was lost. This is why wood cell wall components were oxidized due to oxygen in the hot air, which was used as the heat transfer media in the hot air heat treatment. This mass loss is difficult to decrease. Consequently, the combined treatment has advantages in that the amount of degraded wood cell components was lower and the mass loss by heat treatment could be decreased by recovery compared with the hot air heat treatment.

\section{Conclusions}

The relative percentage content of xylan, mannan, galactan, and arabinan was decreased, whereas that of the Klason lignin was increased, additionally, that of glucan and extractives remained almost unchanged. Lignin may bind with furan compounds decomposed from hemicellulose following heat treatment, thus contributing to the increase in the apparent relative percentage contents of the Klason lignin. In the gas and liquid condensate collected in the condenser after the combined treatment, large amounts of chemicals degraded from hemicellulose were detected. In particular, significant amounts of sugars degraded from cellulose and hemicellulose were detected in the liquid condensate.

Acknowledgements This work was financially supported by the Forest Science and Technology Projects (S121315L010100) provided by Korea Forest Service and the Basic Science Research Program through the National Research Foundation of Korea (NRF) funded by the Ministry of Science, ICT and future Planning (NRF2015R1D1A1A01060308).

\section{References}

1. Militz H (2002) Heat treatment technologies in Europe: scientific background and technological state of art. In: Proceedings of conference on enhancing the durability of lumber and engineered wood products. Forest Products Society, Kissimmee, Orlando, Madison, USA

2. Repellin V, Guyonnet R (2005) Evaluation of heat-treated wood swelling by differential scanning calorimetry in relation to chemical composition. Holzforschung 59(1):28-34

3. Esteves BM, Graça J, Pereira HM (2008) Extractive composition and summative chemical analysis of thermally treated eucalypt wood. Holzforschung 62(3):344-351

4. Tuong VM, Li J (2011) Changes caused by heat treatment in chemical composition and some physical properties of acacia hybrid sapwood. Holzforschung 65(1):67-72

5. Kim YH, Lee SM, Lee HW, Lee JW (2012) Physical and chemical characteristics of products from the torrefaction of yellow poplar (Liriodendron tulipifera). Bioresour Technol 116:120-125
6. Ferrari S, Allegretti O, Cuccui I, Moretti N, Marra M, Todaro L (2013) A revaluation of Turkey oak wood (Quercus cerris L.) through combined steaming and thermo-vacuum treatments. BioResources 8(4):5051-5066

7. Yang Y, Zhan TY, Lu JX, Jiang JH (2015) Influence of thermovacuum treatment on colors and chemical compositions of alder birch wood. BioResources 10(4):7936-7945

8. Wang Z, Yang X, Sun B, Chai Y, Liu J, Cao J (2016) Effect of vacuum heat treatment on the chemical composition of larch wood. BioResources 11(3):5743-5750

9. Tjeerdsma BF, Militz H (2005) Chemical changes in hydrothermal wood: FTIR analysis of combined hydrothermal and dry heat-treated wood. Holz Roh Werkst 63(2):102-111

10. Boonstra MJ, Tjeerdsma B (2006) Chemical analysis of heat treated softwoods. Holz Roh Werkst 64(3):204-211

11. Esteves BM, Pereira HM (2009) Wood modification by heat treatment: a review. BioResources 4(1):370-404

12. Wikberg H, Maunu SL (2004) Characterisation of thermally modified hard- and softwoods by 13C CPMAS NMR. Carbohydr Polym 58(4):461-466

13. Nuopponen M, Vuorinen T, Jämsä S, Viitaniemi P (2003) The effects of heat treatment on the behaviour of extractives in softwood studied by FTIR spectroscopic methods. Wood Sci Technol 37:109-115

14. Kim OS, Lee DH, Chun WP (2008) Eco-friendly drying technology using superheated steam. Korean Chem Eng Res 46(2):258-273

15. Park Y, Eom CD, Han Y, Park JH, Chang YS, Yang SY, Choi JW, Yeo H (2014) Combined treatment of green pitch pine wood by heat and superheated steam and the effects on physical properties of the products. Holzforschung 68(3):327-335

16. Sluiter A, Hames B, Ruiz R, Scarlata C, Sluiter J, Templeton D (2006) Determination of sugars, byproducts, and degradation products in liquid fraction process samples. National Renewable Energy Laboratory, Golden, pp 3-9

17. Jang SK, Kim HY, Jeong HS, Kim JY, Yeo H, Choi IG (2016) Effect of ethanol organosolv pretreatment factors on enzymatic digestibility and ethanol organosolv lignin structure from Liriodendron tulipifera in specific combined severity factors. Renew Energy 87:599-606

18. Jeong HS, Jang SK, Kim HY, Yeo H, Choi JW, Choi IG (2016) Effect of freeze storage on hemicellulose degradation and enzymatic hydrolysis by dilute-acid pretreatment of Mongolian oak. Fuel 165:145-151

19. Park Y, Park JH, Yang SY, Chung H, Kim H, Han Y, Chang YS, Kim K, Yeo H (2016) Evaluation of physico-mechanical properties and durability of larix kaempferi wood heat-treated by superheated steam. J Korean Wood Sci Technol 44(5):776-784

20. Tjeerdsma BF, Boonstra M, Pizzi A, Tekely P, Militz H (1998) Characterisation of thermally modified wood: molecular reasons for wood performance improvement. Holz Roh Werkst 56:149-153

21. Weiland JJ, Guyonnet R (2003) Study of chemical modifications and fungi degradation of thermally modified wood using DRIFT spectroscopy. Holz Roh Werkst 61(3):216-220

22. Yao C, Yongming F, Jianmin G, Li Houkun (2012) Coloring characteristics of in situ lignin during heat treatment. Wood Sci Technol 46:33-40

23. Bourgois J, Guyonnet R (1988) Characterization and analysis of torrefied wood. Wood Sci Technol 22(2):143-155 